\title{
Exosomal IncRNAs from mesenchymal stem cells as the novel modulators to cardiovascular disease
}

\author{
Ying Huang
}

\begin{abstract}
Aim: Mesenchymal stem cells (MSCs) have been identified as potential therapeutic candidates for cardiovascular disease (CVD). However, the molecular mechanism underlying their therapeutic effects is unknown.

Findings: Recently, Chen et al. showed that an exosomal IncRNA derived from MSCs protected against cardiomyocyte apoptosis in vivo, which provided new insight into our understanding of the functions of MSCs. Other exosomal IncRNAs from MSCs have been shown to play pivotal roles in the development of CVD.

Conclusion: Exosomal IncRNAs are important molecules in the application of MSCs, which reveals, at least in part, the functional mechanism of MSCs.
\end{abstract}

\section{Dear Editor,}

Cardiovascular disease (CVD) is the leading cause of morbidity and mortality worldwide. Mesenchymal stem cells (MSCs) were identified as potential therapeutic candidates for CVD many years ago. Delivery of MSCs decreased infarcted size, improved cardiac function, regulated cardiac cell function, and provided a histological network for cell attachment. However, the underlying molecular mechanism remains to be elucidated.

Exosomes have recently been shown to be important mediators of cell-to-cell communication. Exosomes are lipid bilayer-enclosed nanovesicles containing multiple molecules, including proteins, DNAs, and RNAs, that can transfer biological information under both normal physiological and pathological conditions. Recently, Chen et al. reported that exosomal long non-coding RNA (lncRNA) derived from MSCs protected cardiomyocytes against apoptosis in vivo, which provided new insight into our understanding of the functional role of MSCs. According to the study, lncRNA-NEAT1 derived from exosomes

\footnotetext{
Correspondence: ayfyhy@126.com

Department of Cardiology, The First Affiliated Hospital of Anhui Medical University, Hefei 230032, China
}

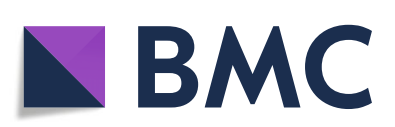

(c) The Author(s). 2020 Open Access This article is licensed under a Creative Commons Attribution 4.0 International License, which permits use, sharing, adaptation, distribution and reproduction in any medium or format, as long as you give appropriate credit to the original author(s) and the source, provide a link to the Creative Commons licence, and indicate if changes were made. The images or other third party material in this article are included in the article's Creative Commons licence, unless indicated otherwise in a credit line to the material. If material is not included in the article's Creative Commons licence and your intended use is not permitted by statutory regulation or exceeds the permitted use, you will need to obtain permission directly from the copyright holder. To view a copy of this licence, visit http://creativecommons.org/licenses/by/4.0/ The Creative Commons Public Domain Dedication waiver (http://creativecommons.org/publicdomain/zero/1.0/) applies to the data made available in this article, unless otherwise stated in a credit line to the data.

prepared from macrophage migration inhibitory factor (MIF)-induced MSCs blocked $\mathrm{H}_{2} \mathrm{O}_{2}$-induced apoptosis in cardiomyocytes by modulating the expression of miR-142$3 p$ and activating Forkhead class O1 (FOXO1). This finding suggests the potential of exosomal lncRNA-mediated therapy for clinical applications [1].

Similar to lncRNA-NEAT1, other MSC-derived exosomal lncRNAs showed activity in CVD. Exosomal metastasis-associated lung adenocarcinoma transcript 1 (MALAT1), derived from human umbilical cord MSCs, blocked aging-induced cardiac dysfunction by inhibiting the nuclear factor kappa B (NF-kB)/tumor necrosis factor- $\alpha$ (TNF- $\alpha)$ signaling pathway [2]. In addition, atorvastatin pretreatment reduced cardiomyocyte apoptosis, attenuated increases in interleukin 6 (IL-6) and TNF- $\alpha$, improved cardiac function, promoted endothelial cell survival, and reduced infarct size, and these activities were associated with increased expression of the exosomal lncRNA H19 and activation of miR-675, vascular endothelial growth factor (VEGF), and intercellular adhesion molecule-1 (ICAM-1) [3]. Overexpression of the exosomal lncRNA KLF3-AS1 from MSCs decreased cell apoptosis and pyroptosis and the myocardial 
infarction size by suppressing miR-138-5p and regulating silent mating type information regulation 2 homolog-1 (Sirt1) expression [4].

Taken together, these findings demonstrate that exosomal lncRNAs are important molecules in the application of MSCs, and at least partially reveal the functional mechanism underlying the effects of MSCs. Nevertheless, our understanding of the precise regulatory mechanisms of exosomal lncRNAs in different cells is still in its infancy. For example, while it is known that some lncRNAs are expressed at low levels in cells but are enriched in secreted exosomes, how the exosome "captures" these IncRNA molecules is yet unknown. Although lncRNAs may have a better chance of escaping ribonuclease degradation through their association with exosomes, it is not known whether lncRNAs are modified within the exosome. In addition, lncRNAs, miRNAs, and mRNAs can be regulated by other molecules, which makes determining the regulatory relationships challenging. Therefore, further study is needed to fully understand the characteristics of exosomal lncRNAs.

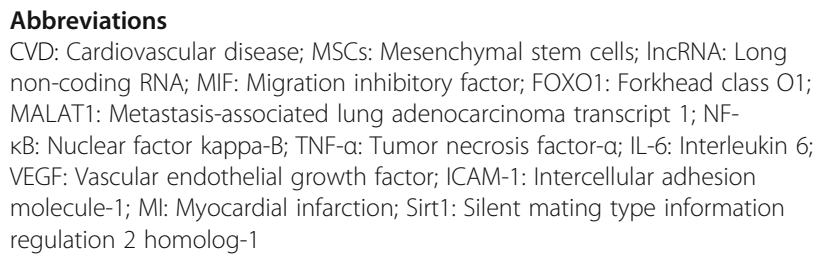

\section{Acknowledgements}

Not applicable.

\section{Author's contributions}

Ying Huang wrote the letter. The author read and approved the final manuscript.

\section{Funding}

Not applicable.

Availability of data and materials

Not applicable.

Ethics approval and consent to participate

Not applicable.

\section{Consent for publication}

Not applicable.

\section{Competing interests}

The author confirms that this article content has no conflicts of interest.

Received: 18 February 2020 Revised: 1 April 2020

Accepted: 6 July 2020 Published online: 23 July 2020

\section{References}

1. Chen $\mathrm{H}$, Xia W, Hou M. LncRNA-NEAT1 from the competing endogenous RNA network promotes cardioprotective efficacy of mesenchymal stem cellderived exosomes induced by macrophage migration inhibitory factor via the miR-142-3p/FOXO1 signaling pathway. Stem Cell Res Ther. 2020;11:31.

2. Shang $X$, Lin K, Yu R, Zhu P, Zhang Y, Wang L, Xu J, Chen K. Resveratrol protects the myocardium in sepsis by activating the phosphatidylinositol 3kinases (PI3K)/AKT/mammalian target of rapamycin (mTOR) pathway and inhibiting the nuclear factor-kappaB (NF-kappaB) signaling pathway. Med Sci Monit. 2019;25:9290-8.

3. Huang P, Wang L, Li Q, Tian X, Xu J, Xu J, Xiong Y, Chen G, Qian H, Jin C, Yu Y, Cheng K, Qian L, Yang Y. Atorvastatin enhances the therapeutic efficacy of mesenchymal stem cells-derived exosomes in acute myocardial infarction via up-regulating long non-coding RNA H19. Cardiovasc Res. 2020;116:353-67.

4. Mao Q, Liang XL, Zhang CL, Pang YH, Lu YX. LncRNA KLF3-AS1 in human mesenchymal stem cell-derived exosomes ameliorates pyroptosis of cardiomyocytes and myocardial infarction through miR-138-5p/Sirt1 axis. Stem Cell Res Ther. 2019;10:393.

\section{Publisher's Note}

Springer Nature remains neutral with regard to jurisdictional claims in published maps and institutional affiliations. 